【論文】

UDC : 624.074. $42: 624.04: 519.6$

\title{
極小曲面の変数低減による有限要素解析 FINITE ELEMENT ANALYSIS OF MINIMAL SURFACE BASED ON THE REDUCTION OF VARIABLES
}

\author{
鈴木 俊男*, 半谷裕彦** \\ Toshio SUZUKI and Yasuhiko HANGAI
}

\begin{abstract}
The paper presents an analytical method of minimal surfaces. The basic differential equations with three unknown coordinate functions are derived from the functional for minimal surfaces. The solution of the differential equations is formulated to be the solution having one unknown variable which denotes the length in the given direction from the initial surface to the unknown surface to be determinated. The finite element method is used to the numerical analysis, and the three minimal surfaces are numerically analyzed in order to examine the validity of the proposed method.
\end{abstract}

Keywords : membrane structure, shape analysis, minimal surface, quasi-linear partial differential equation

膜構造，形状解析，極小曲面，準線形偏微分方程式

\section{1. 序 論}

\section{1 はじめに}

膜構造を設計するうえで，第一の作業として膜面の形 状決定がある。膜構造で用いる膜面は, 力学的に最も安 定した曲面である等張力曲面とすることが多い。等張力 曲面は自然界では石䖒水の表面張力によって作られる石 鹼膜の曲面として知られている。一方, 極小曲面とは空 間内の閉曲線が囲む曲面の中で面積が極小となるものを いい, 数学的には等張力曲面は極小曲面と等価であるこ とが知られている。したがって，等張力曲面を求める問 題は極小曲面を求める問題に置き換えることができる。 極小曲面は偏微分方程式および積分方程式の応用例之し て長期間にわたって研究されてきており，その基礎方程 式は確立されている11 31。

極小曲面問題の数値解析法として差分法や有限要素法 等が提案されているが, 解析対象範囲の制限や収束性の 悪さ等の問題点があり, 現在では計算途中の解に何らか の操作を加えながら収束解を得る力法が行われている。 本報告では極小曲面の微分方程式を座標 $X, Y, Z$ の 3 関数によって表し，これを等温直交座標系に変換すると 3 つの独立した調和方程式に帰着できるという数学的性 質に着目して, 解析上の変数を 1 つに低減させることに より収束性が良好な数值解析法について検討するもので ある。

*フジ夕技術研究所

** 東京大学生産技術研究所 教授. I博

\section{2 既往の研究と本研究の目的}

極小曲面の数值解析法についてはこれまでも多くの研

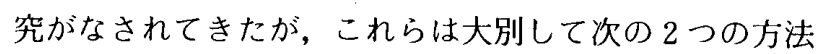
に分けることができる。

第 1 の方法は, 式（1）の極小曲面方程式または式（2） で与えられる汎関数 (面積汎関数) を基礎式として, 差 分法または有限要素法によって解く方法である。

極小曲面方程式：

$$
\left(1+U_{y}^{2}\right) \cdot U_{x x}-2 U_{x} U_{y} \cdot U_{x y}+\left(1+U_{x}^{2}\right) \cdot U_{y y}=0
$$

面積汎関数：

$$
\Pi=\int \sqrt{1+U_{x}^{2}+\bar{U}_{y}^{2}} d x d y
$$

ここに, $U$ は直交座標系 0- $X Y Z$ における曲面を表 す変数で $Z=U(x, y)$ である。また， $U_{x}, U_{y}$ はそれぞ れ $U_{\dot{x}}=\partial U / \partial x, U_{y}=\partial U / \partial y$ である。

第 2 の方法は, 等張力曲面の観点から, 式 (3) で定 義される汎関数を用い, 弾性論における初期応力問題と して扱う方法である。

$$
\Pi=\int n_{0} \varepsilon d x d y
$$

ここに， $n_{0}$ は等張力, $\varepsilon$ は求める曲面の初期曲面に 対するひずみである。

まず，第1の方法による研究について述べる。

Greenspan $^{41}$ は, 汎関数 $(2)$ の被積分項に含まれる 
$U$ に関する偏微分係数に対して差分表示式を適用して いる。この方法によると, 極小曲面方程式の差分化に伴 う煩雑さを避けることが示されている。非線形方程式の 数值計算法としては, 遅延因子を用いた一般化された Newton-Raphson 法 (以下，一般 NR 法之略す）を用い ている。解の収束性に影響する要因として, 分割数, 遅 延因子および解法の種類を考え, それらが反復回数と精 度に及ぼす度合いについて考察している。解析例として, 回転懸垂曲面と式 $u=\left[\cosh ^{2} x-y^{2}\right]^{1 / 2}$ で表される曲面 の 2 つの曲面を解析している。Concus ${ }^{5)}$ は, 極小曲面 方程式 (1) を直接差分化する方法により解析している。 非線形方程式の数値計算法としては一般 NR 法を用い ている。その結果, 差分近似の方法の中で $U$ に関する 1 階の偏微分係数には中央差分を用いるとよいこと，お よび解の収束性には遅延因子が大きく影響することの 2 点を指摘している。解析例として, 式 $u=\left[\cosh ^{2} x-\right.$ $\left.y^{2}\right]^{1 / 2}$ で表される曲面を解析している。Otto and Troste $^{6 !}$ は, 式 (1) の極小曲面方程式において境界 条件を満足するFourier 級数解を用いて HP 曲面を解析 している。項数を 2 項まで取ると精度は数％の誤差と なることが示されている。Ishii and Suzuki”) は, 極小 曲面方程式（1）に差分法を適用している。非線形方程 式の数値計算法としては Gauss-Seidel 法を採用してい る。解析例は HP 曲面で, 分割数と収束性の関係を検 討している。Hinata, Shimasaki and Kiyono ${ }^{8)}$ は, 面 積汎関数（2）に有限要素法を適用している。汎関数を 積分して陽な形で求めた結果, 座標値 $X, Y, U$ は互い に循環性があることを指摘し，このことから未知量とし て $X, Y, U$ のいずれを選んでもよいことを示してい る。非線形方程式の数値計算法としては一般 NR 法を 用いている。解析例として回転懸垂面とWienerDouglas 問題 ${ }^{9}$ を解析している。前者の曲面では精度の 検討を, 後者の曲面では開口角と高さをパラメータとし た時の曲面の存在範囲を明らかにしている。

次に，第 2 の方法による研究について述べる。この方 法の特徵は, 汎関数を初期応力がなす弾性ポテンシャル エネルギーとすること, および未知量が座標值 $X, Y$, $Z$ の 3 変数とするこ亡, の 2 点である。

Haug and Powell ${ }^{10)}$ は, 式 (3) の汎関数に有限要素 法を適用している。要素は四辺形要素とし, 空間上での 要素のゆがみを表現できる斜交座標系を用いている。応 力 $n_{0}$ は才イラー応力, ひずみ $\varepsilon$ は変形後の第 1 基本計 量としている。非線形方程式の数值計算法としては Newton-Raphson 法を用いている。解析例として簡単な サスペンション膜形状を解析している。Barnes ${ }^{111}$ は動 的緩和法 (DR 法) を用いて膜形状を解析している。釣 合式は三角形要素の要素力を幾何学的関係から直接求め ることで導いている。質量マトリックスと減衰マトリッ
クスを追加し, 初期状態から最終位置までを動的に追跡 している。この方法により動的不安定状態から安定状態 へ移動させることができることを二〜三の解析例により 示している。石井 ${ }^{12)}$ は, 応力 $n_{0}$ をオイラ一応力, ひず みを要素の変形前後の面積変化率として定義し, 有限要 素法を用いて解析している。非線形方程式の数值計算法 としては Newton-Raphson 法を採用している。增分剛 性として釣合式の厳密な接線剛性の代わりに幾何剛性を 用いることによって解の収束性を改良させている。解析 例として境界形状が複雑な膜構造を解析している。安

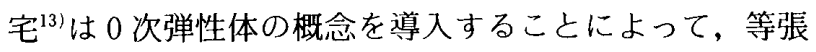
力曲面の形状決定という幾何学の問題が通常の弾性論を 拡張することで取り扱えることを理論的に考察してい る。本間ら ${ }^{(4)}$ は, 石井 ${ }^{12}$ の方法の内, 数值計算法として 一般 NR 法を用い，増分剛性として釣合式の厳密な接 線剛性を用いた解析法を示している。解析例として実際 のサスペンション膜を解析している。大森ら ${ }^{15}$ は, 石井 ${ }^{121}$ の方法の内, 増分剛性として釣合式の厳密な接線剛性を 用いた解析法を示している。初期曲面と極小曲面とで囲 まれた空間の内容積を指定することによって収束性の改 善を計っている。解析例として回転懸垂面と複雑なサス ペンション膜を解析している。

次に, 既往の 2 方法における問題点を述べる。

まず，極小曲面方程式（1）を基にした第 1 の方法に 関する問題点は次のとおりである。

(1) 曲面上の微係数 $U_{x}, U_{y}$ が大きくなる場合解の精度 が落ちる。

(2) 未知量が多価となる曲面は解析できない。

(3) 差分法およびそれに類した解析では収束回数が大き い。

第 2 の方法は第 1 の方法のように解析の制約がないこ とおよび定式化が容易であることの利点はあるが，実際 の計算では解が収束しない場合が多い。問題点を整理す ると次のようになる。

(1) 初期値を正解から離して設定すると収束しない場合 が生じる。

(2) 収束解が得られても各要素の面積が不均一となり, 応力解析用の要素分割には不適当となる曲面が得られる 場合がある。

(3) 収束解を得るためには, 初期曲面, 一般 NR 法で 用いる遅延因子および増分剛性を問題によって試行錯誤 的に設定する必要がある。

以上が既往の研究における問題点の概要である。これ らの問題を要約すると次のように言える。

膜構造の設計に必要となる極小曲面を設計条件に適合 した任意の境界形状に対して求めるためには，極小曲面 を $Z=U(x, y)$ の形で表す解析ではなく, 極小曲面の座 標関数として $X, Y, Z$ を用いた解析が必要となる。し 
かし，3つの座標関数をすべて変数として扱うといった 汎関数に初期応力のなす弾性ポテンシャルを用いる方法 では, 本来 3 個の座標関数間に 1 個の関係式が存在する にもかかわらず，この関係式を無視しているため収束性 が極めて悪い。

以上を基とし本論文では, 第 1 と第 2 の手法の利点を 取り込んだ次のような手法を提案し検討する。

極小曲面の基礎式として 3 つの座標関数で表された連 続体表現の汎関数を用いることとする。これは, 第 1 の 方法で用いた基礎式の曲面積を一般の曲面パラメータで 表した曲面積に拡張したものである。この汎関数の停留 条件より導かれる釣合方程式は 3 座標関数 $X, Y, Z$ に 関する非線形偏微分方程式となるが，この方程式は等温 直交関係を満足する座標系に座標変換を施すことによっ て 3 座標関数に関する独立した調和方程式に変換され る。このことから 3 つの座標関数は 1 つの共通の関数で 表すことができるという性質があり，本論文ではこの 1 つの共通な関数を未知変数とし，この変数に初期曲面か らのびた任意の方向をもつ距離べクトルの大きさという 意味をもたせた解析手法を提案する。

\section{2. 極小曲面の基礎式と一般解}

\section{1 極小曲面の基礎方程式}

本論文の極小曲面は式（1）を一般化して次のように 定義する。

「任意の曲面パラメータ $(\alpha, \beta)$ を採用し, 曲面形状を $X$ $=X(\alpha, \beta), \quad Y=Y(\alpha, \beta), Z=Z(\alpha, \beta)$ で表す時, 極小曲 面とは, 汎関数

$$
\Pi=\int H d \alpha d \beta
$$

を極小とする曲面のことをいう。ここに，

$$
\begin{aligned}
& H=\sqrt{g_{\alpha \alpha} g_{\beta \beta}-g_{\alpha \beta}{ }^{2}} \cdots \cdots \cdots \\
& g_{\alpha \alpha}=X_{\alpha}^{2}+Y_{\alpha}^{2}+Z_{\alpha}^{2} \cdots \cdots \cdots \\
& g_{\beta \beta}=X_{\beta}^{2}+Y_{\beta}^{2}+Z_{\beta}^{2} \cdots \cdots \cdots \\
& g_{\alpha \beta}=X_{\alpha} X_{\beta}+Y_{\alpha} Y_{\beta}+Z_{\alpha} Z_{\beta} \\
& X_{\alpha}=\partial X / \partial \alpha \text { 等 }
\end{aligned}
$$

である。」

また, 式（4）のオイラ一方程式は次式となる。

$$
\begin{aligned}
& \frac{\partial}{\partial \alpha}\left(\frac{\partial H}{\partial X_{\alpha}}\right)+\frac{\partial}{\partial \beta}\left(\frac{\partial H}{\partial X_{\beta}}\right)=0 \\
& \frac{\partial}{\partial \alpha}\left(\frac{\partial H}{\partial Y_{\alpha}}\right)+\frac{\partial}{\partial \beta}\left(\frac{\partial H}{\partial Y_{\beta}}\right)=0 \\
& \frac{\partial}{\partial \alpha}\left(\frac{\partial H}{\partial Z_{a}}\right)+\frac{\partial}{\partial \beta}\left(\frac{\partial H}{\partial Z_{\beta}}\right)=0
\end{aligned}
$$

上式の三式をまとめて次のように書き直す。

$$
\begin{aligned}
& \frac{\partial}{\partial \alpha}\left(\frac{\partial H}{\partial r_{\alpha}}\right)+\frac{\partial}{\partial \beta}\left(\frac{\partial H}{\partial r_{\beta}}\right)=0 \\
& \text { ここに, } \boldsymbol{r}_{\alpha} \text { と } \boldsymbol{r}_{\boldsymbol{\beta}} \text { は } \\
& r_{\alpha}=\left(X_{\alpha}, Y_{\alpha}, Z_{\alpha}\right)
\end{aligned}
$$

$r_{\beta}=\left(X_{\beta}, Y_{\beta}, Z_{\beta}\right)$

と表されるべクトルである。

次に, 式（8）を展開すると最終的に次式となる。

$(1 / H) \boldsymbol{q}+\left(-1 / H^{3}\right)\left\{\boldsymbol{f}_{\boldsymbol{\alpha}}\left\langle\boldsymbol{q}, \boldsymbol{r}_{\boldsymbol{\alpha}}\right\rangle+\boldsymbol{f}_{\boldsymbol{\beta}}\left\langle\boldsymbol{q}, \boldsymbol{r}_{\boldsymbol{\beta}}\right\rangle\right\}=0$

ここに,

$$
\begin{aligned}
& \boldsymbol{q}=g_{\beta \beta} \boldsymbol{r}_{\alpha \alpha}-2 g_{\alpha \beta} \boldsymbol{r}_{\alpha \beta}+g_{\alpha \alpha} \boldsymbol{r}_{\beta A} \\
& \boldsymbol{f}_{\alpha}=\boldsymbol{r}_{\alpha} g_{\beta \beta}-g_{\alpha \beta} \boldsymbol{r}_{\beta} \ldots \ldots \ldots \ldots \ldots \ldots \ldots \ldots \ldots \ldots \ldots \ldots \ldots \\
& \boldsymbol{f}_{\boldsymbol{\beta}}=\boldsymbol{r}_{\beta} g_{\alpha \alpha}-g_{\alpha \beta} \boldsymbol{r}_{\alpha} \ldots \ldots \ldots \ldots \ldots \ldots
\end{aligned}
$$

$\left\langle\boldsymbol{q}, \boldsymbol{r}_{\alpha}\right\rangle$ はベクトル $\boldsymbol{q}, \boldsymbol{r}_{\alpha}$ の内積を示す。

したがって

$$
\boldsymbol{q}=\mathbf{0}
$$

は式（10）を満足する。そこで本論文では上式を基礎式 として採用する。つまり式 (11) より

$$
g_{\beta \beta} r_{\alpha \alpha}-2 g_{\alpha \beta} r_{\alpha \beta}+g_{\alpha \alpha} r_{\beta \beta}=0 \text {. }
$$

である。上式を元の未知量 $X, Y, Z$ に戻すと,

$$
\begin{aligned}
& g_{\beta \beta} X_{\alpha \alpha}-2 g_{\alpha \beta} X_{\alpha \beta}+g_{\alpha \alpha} X_{\beta \beta}=0 \cdots \cdots \cdots(15-1) \\
& g_{\beta \beta} Y_{\alpha \alpha}-2 g_{\alpha \beta} Y_{\alpha \beta}+g_{\alpha \alpha} Y_{\beta \beta}=0 \cdots \cdots \cdots(15-2) \\
& g_{\beta \beta} Z_{\alpha \alpha}-2 g_{\alpha \beta} Z_{\alpha \beta}+g_{\alpha \alpha} Z_{\beta \beta}=0 \cdots \cdots \cdots(15-3)
\end{aligned}
$$

となる。

式（14）または式（15）は末知量が $X, Y, Z$ に関す る準線形連立 2 階非線形偏微分方程式であり,この式が 本論文における極小曲面の基礎方程式となる。

2.2 極小曲面の一般解

式（15）で表された極小曲面の基礎方程式において, 2 階偏微分 $X_{\alpha \alpha}, X_{\alpha \beta}, X_{\beta \beta}$ 等の係数 $g_{\beta \beta}, g_{\alpha \beta}, g_{\alpha \alpha}$ は 1 階偏微分の 2 乗を含む非線形項となっており，このまま では解を見いだすことができない。しかし，この式を曲 面上の点 $(\alpha, \beta)$ において, 等温直交関係式

$$
\begin{aligned}
& g_{\xi \xi}=g_{n \eta} \\
& g_{s \eta}=0 \cdots
\end{aligned}
$$

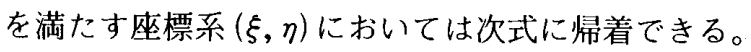

$$
\begin{aligned}
& \frac{\partial^{2} X}{\partial \xi^{2}}+\frac{\partial^{2} X}{\partial \eta^{2}}=0 \\
& \frac{\partial^{2} Y}{\partial \xi^{2}}+\frac{\partial^{2} Y}{\partial \eta^{2}}=0 \\
& \frac{\partial^{2} Z}{\partial \xi^{2}}+\frac{\partial^{2} Z}{\partial \eta^{2}}=0
\end{aligned}
$$

文献 1) を参照して, 式（17）の解を以下のように求 める。式 (17) は $X, Y, Z$ に関して同一の調和方程式 となっている。そこで, 調和方程式

$$
\frac{\partial^{2} a}{\partial \xi^{2}}+\frac{\partial^{2} a}{\partial \eta^{2}}=0
$$

を考え, $X, Y, Z$ を $a(\xi, \eta)$ の関数として次のように表 す。

$$
\begin{aligned}
& X=X(a) \\
& Y=Y(a) \\
& Z=Z(a)
\end{aligned}
$$


式（19）を式（17）に代入し， $X(a), Y(a), Z(a)$ の形 式を求める。

式（19-1）を式（17-1）に代入すると

$$
\frac{\partial^{2} X}{\partial \xi^{2}}+\frac{\partial^{2} X}{\partial \eta^{2}}=0
$$

また，式 (19-1) より

$$
\begin{aligned}
& \frac{\partial X}{\partial \xi}=\frac{d X}{d a} \frac{\partial a}{\partial \xi} \\
& \frac{\partial X}{\partial \eta}=\frac{d X}{d a} \frac{\partial a}{\partial \eta} \\
& \frac{\partial^{2} X}{\partial \xi^{2}}=\frac{\partial}{\partial \xi}\left(\frac{d X}{d a}\right) \cdot \frac{\partial a}{\partial \xi}+\frac{d X}{d a} \cdot \frac{\partial}{\partial \xi}\left(\frac{\partial a}{\partial \xi}\right) \\
& =\frac{d^{2} X}{d a^{2}}\left(\frac{\partial a}{\partial \xi}\right)^{2}+\frac{d X}{d a} \cdot \frac{\partial^{2} a}{\partial \xi^{2}} . \\
& \frac{\partial^{2} X}{\partial \eta^{2}}=\frac{d^{2} X}{d a^{2}}\left(\frac{\partial a}{\partial \eta}\right)^{2}+\frac{d X}{d a} \cdot \frac{\partial^{2} a}{\partial \eta^{2}} \text {. }
\end{aligned}
$$

式 (21-3) と式 (21-4) を（20）に代入すると次式と なる。

$$
\frac{d^{2} X}{d a^{2}}\left\{\left(\frac{\partial a}{\partial \xi}\right)^{2}+\left(\frac{\partial a}{\partial \eta}\right)^{2}\right\}+\frac{d X}{d a}\left(\frac{\partial^{2} \mathrm{a}}{\partial \xi^{2}}+\frac{\partial^{2} a}{\partial \eta^{2}}\right)=0
$$

ところで, 左辺第 2 項の $\left(\frac{\partial^{2} a}{\partial \xi^{2}}+\frac{\partial^{2} a}{\partial \eta^{2}}\right)$ は式 (18) よ り 0 となるが, 左辺第 1 項の $\left\{\left(\frac{\partial a}{\partial \xi}\right)^{2}+\left(\frac{\partial a}{\partial \eta}\right)^{2}\right\}$ は一般 的に0とはならないので上式が成立するためには

$$
\frac{d^{2} X}{d a^{2}}=0
$$

となる必要がある。

式 (23) を 2 回積分すると

$$
X=c_{1} a+c_{2}
$$

となり， $X$ の形式は $a$ の一次式となることが分かる。 ここに， $c_{1}, c_{2}$ は積分定数である。

同様に， $Y, Z$ についても次のように表せる。

$$
\begin{aligned}
& Y=d_{1} a+d_{2} \\
& Z=e_{1} a+e_{2}
\end{aligned}
$$

上式から， $X, Y, Z$ は互いに独立した変数ではなく, $a$ という共通の函数によって結び付けられた従属関係に ある変数であることが分かる。

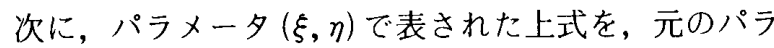
メ一 $(\alpha, \beta)$ に変換すると, 最終的に極小曲面の基礎式

（15）の一般解は, 次式となる。

$$
\begin{aligned}
& X=\lambda(\alpha, \beta) a(\alpha, \beta)+x_{0}(\alpha, \beta) \\
& Y=\mu(\alpha, \beta) a(\alpha, \beta)+y_{0}(\alpha, \beta) \\
& Z=\nu(\alpha, \beta) a(\alpha, \beta)+z_{0}(\alpha, \beta)
\end{aligned}
$$

ここに, $a(\alpha, \beta)$ が未知量で, $\lambda ; \mu, \nu, x_{0}, y_{0}, z_{0}$ は, 積分定数である。

上式と似た形式の式は文献 5)にも紹介されているが, 本報告では， $\lambda, \mu, \nu$ と $x_{0}, y_{0}, z_{0}$ を $\alpha, \beta$ の関数で任意 に定める量しした。上式の物理的意味は; 図一1で示さ

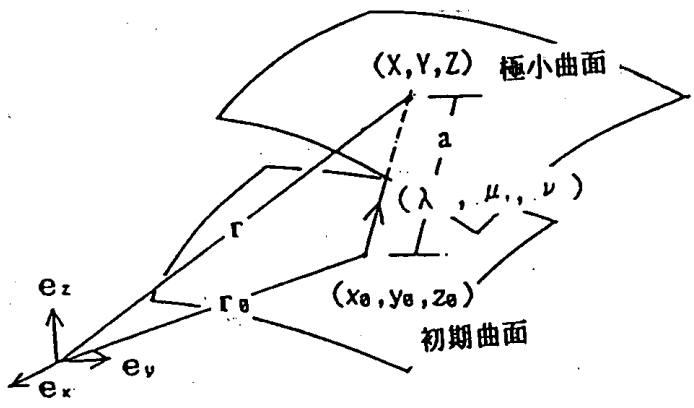

図一1：曲面を決定する未知量 $a$ とその方向余弦

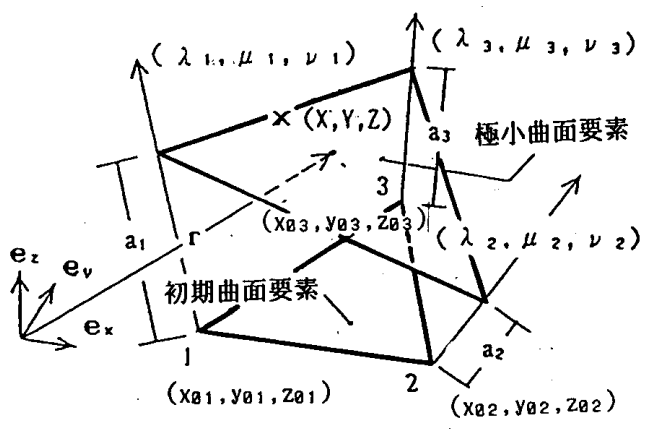

図一2 三角形要素による曲面表示

れるように $x_{0}, y_{0}, z_{0}$ を初期曲面とし， $\lambda ， \mu, \nu$ を初期 曲面で設定された方向余弦としたとき，極小曲面を表す 座標 $X, Y, Z$ は, 初期曲面上の座標 $x_{0}, y_{0}, z_{0}$ と方向 余弦方向の距離 $a$ の和として求められることである。

極小曲面の汎関数（4）に上式の一般解（25）を代入 する。この結果，極小曲面を表す未知量は一変数 $a(\alpha$, 及)に低減されたことになる。

\section{3. 有限要素法による定式化}

前章で求めた極小曲面を表す一般解 (25) と汎関数(4) を用いた有限要素法について述べる。

ここでは， 3 角形要素を用いる。図一 2 に，初期曲面 と極小曲面上の座標および方向余弦を示す。 $a_{1} \sim a_{3}$ は それぞれ節点 1 〜 における末知量 $a$ を表している。

ここで,

$x_{0 i}, y_{0 i}, z_{0 i}$ : 初期曲面上の節点 $i$ の座標 $x_{0 e}, y_{0 e}, z_{0 e}:$ 初期曲面上の要素内部の座標

$x_{i}, y_{i}, z_{i}$ : 極小曲面上の節点 $i$ の座標

$x_{e}, y_{e}, z_{e}:$ 極小曲面上の要素内部の座標

$\lambda_{x i}, \lambda_{y i}, \lambda_{z i}:$ 節点 $i$ の方向余弦

$$
a_{i} \text { : 節点 } i \text { の距離 (未知量) }
$$

また，次の記号を定義する。

$$
\begin{aligned}
& \boldsymbol{X}_{0 i}={ }^{t}\left|\begin{array}{lllllllll}
x_{01} & x_{02} & x_{03} & y_{01} & y_{02} & y_{03} & z_{01} & z_{02} & z_{03}
\end{array}\right| \\
& \left.\boldsymbol{X}_{0 e}={ }^{4} x_{0 e} \quad y_{0 e} \quad z_{0 e}\right\} \cdots \cdots \cdots \cdots \cdots \cdots \cdots \cdots \cdots \cdots \cdots \cdots \cdots \cdots \cdots \cdots \cdots(26-2) \\
& \left.\boldsymbol{X}_{i}={ }^{t} \mid x_{1} \quad x_{2} x_{3} \quad y_{1} \quad y_{2} \quad y_{3} \quad z_{1} \quad z_{2} \quad z_{3}\right\} \cdots(26-3) \\
& \boldsymbol{X}_{e}={ }^{t}\left\{x_{e} \quad y_{e} \quad z_{e}\right\} \cdots \cdots \cdots \cdots \cdots \cdots \cdots \cdots \cdots \cdots \cdots \cdots \cdots \cdots \cdots \cdots \cdots \cdots(26-4)
\end{aligned}
$$




$$
\begin{aligned}
& \Lambda_{x}=\left[\begin{array}{ccc}
\lambda_{1} & \cdot & \cdot \\
\cdot & \lambda_{2} & \cdot \\
\cdot & \cdot & \lambda_{3}
\end{array}\right], \quad \Lambda_{y}=\left[\begin{array}{ccc}
\mu_{1} & \cdot & \cdot \\
\cdot & \mu_{2} & \cdot \\
\cdot & \cdot & \mu_{3}
\end{array}\right] \text {, } \\
& \Lambda z=\left[\begin{array}{ccc}
\nu_{1} & \cdot & \cdot \\
\cdot & \nu_{2} & \cdot \\
\cdot & \cdot & \nu_{3}
\end{array}\right] \\
& \boldsymbol{a}_{i}={ }^{t}\left\{\begin{array}{lll}
a_{1} & a_{2} & a_{3}
\end{array}\right\}
\end{aligned}
$$

式 (25) より極小曲面上の節点座標 $x_{i}$ は, 初期曲面 上の節点座標 $\boldsymbol{x}_{0 i}$ と節点距離 $\boldsymbol{a}_{i}$ とにより, 次のように 表される。

$$
x_{i}=x_{0 i}+\Lambda \cdot a_{i}
$$

ここに

$$
\Lambda=\left[\begin{array}{l}
\Lambda_{x} \\
\Lambda_{y} \\
\Lambda_{z}
\end{array}\right]
$$

また, 要素内部の座標 $\boldsymbol{x}_{e}$ は要素節点座標 $\boldsymbol{x}_{i}$ で表す ことができる。つまり

$$
\begin{aligned}
\boldsymbol{x}_{\boldsymbol{e}}= & {\left[\begin{array}{lllllllll}
1 & \cdot & \cdot & 1 & \cdot & \cdot & 1 & \cdot & \cdot \\
\cdot & x & \cdot & \cdot & x & \cdot & \cdot & x & \cdot \\
\cdot & \cdot & y & \cdot & \cdot & y & \cdot & \cdot & y
\end{array}\right] } \\
& \cdot\left[\begin{array}{ccc}
\boldsymbol{A} & \cdot & \cdot \\
\cdot & \boldsymbol{A} & \cdot \\
\cdot & \cdot & \boldsymbol{A}
\end{array}\right] \boldsymbol{x}_{\boldsymbol{i}} \\
& =\boldsymbol{U}(\boldsymbol{x}, y) \cdot \boldsymbol{x}_{i} \\
& =\boldsymbol{U} \cdot\left(\boldsymbol{x}_{0 i}+\boldsymbol{\Lambda} \cdot \boldsymbol{a}_{i}\right)
\end{aligned}
$$

上式が, 極小曲面上の要素内部の座標 $x_{e}$ を, 節点距 離 $\boldsymbol{a}_{i}$ で表したもので, 今後第 1 基本計量を計算すると きの基本となるものである。

つぎに, 要素座標系をデカルト座標で表し, 要素の汎 関数を次式で定義する。

$$
\Pi_{e}=\int \sqrt{g_{x x} g_{y y}-g_{x y}{ }^{2}} d x d y
$$

極小曲面上の位置ベクトルは

$$
\boldsymbol{r}=x_{e} \boldsymbol{e}_{x}+y_{e} \boldsymbol{e}_{y}+z_{e} \boldsymbol{e}_{z}
$$

で表されるから，第 1 基本計量は次式となる。

$$
\begin{aligned}
& g_{x x}=\left(\frac{\partial x_{e}}{\partial x}\right)^{2}+\left(\frac{\partial y_{e}}{\partial x}\right)^{2}+\left(\frac{\partial z_{e}}{\partial x}\right)^{2} \cdots \cdots \ldots . . \\
& g_{y y}=\left(\frac{\partial x_{e}}{\partial y}\right)^{2}+\left(\frac{\partial y_{e}}{\partial y}\right)^{2}+\left(\frac{\partial z_{e}}{\partial y}\right)^{2} \ldots \ldots \ldots \\
& g_{x y}=\frac{\partial x_{e}}{\partial x} \frac{\partial x_{e}}{\partial y}+\frac{\partial y_{e}}{\partial x} \frac{\partial y_{e}}{\partial y}+\frac{\partial z_{e}}{\partial x} \frac{\partial z_{e}}{\partial y} . \cdots
\end{aligned}
$$

式 (31) から

$$
\begin{aligned}
& \left\{\begin{array}{l}
\partial x_{e} / \partial x \\
\partial y_{e} / \partial x \\
\partial z_{e} / \partial x
\end{array} \mid=\frac{\partial \boldsymbol{U}}{\partial x} \cdot \boldsymbol{x}_{i}=\boldsymbol{U}_{x} x_{i}\right. \\
& \left\{\begin{array}{l}
\partial x_{e} / \partial y \\
\partial y_{e} / \partial y \\
\partial z_{e} / \partial y
\end{array}\right\}=\frac{\partial \boldsymbol{U}}{\partial y} \cdot \boldsymbol{x}_{i}=\boldsymbol{U}_{y} \boldsymbol{x}_{i}
\end{aligned}
$$

式（35）を式（34）に代入すると

$$
\begin{aligned}
& g_{x x}={ }^{t} \boldsymbol{x}_{i}{ }^{t} \boldsymbol{U}_{\boldsymbol{x}} \boldsymbol{U}_{x} \boldsymbol{x}_{\boldsymbol{i}} \\
& g_{y y}={ }^{t} \boldsymbol{x}_{i}{ }^{t} \boldsymbol{U}_{y} \boldsymbol{U}_{y} \boldsymbol{x}_{\boldsymbol{i}}{ }{ } \\
& g_{x y}={ }^{t} \boldsymbol{x}_{\boldsymbol{i}}{ }^{t} \boldsymbol{U}_{x} \boldsymbol{U}_{y} \boldsymbol{x}_{i}{ }{ }
\end{aligned}
$$

次に, 第 1 基本計量のベクトル表示を次の形で示す。

$$
\boldsymbol{g}={ }^{t}\left\{g_{x x} g_{y y} g_{x y}\right\}
$$

さらに, $\boldsymbol{g}$ の変分を式 (36) と式 (37) から求める之, $\delta x_{i}$ を用いて次のように表すことができる。

$$
\delta g=V \cdot \delta x_{i}
$$

ここに,

$$
\boldsymbol{V}=\left[\begin{array}{l}
2^{t} \boldsymbol{x}_{i}{ }^{t} \boldsymbol{U}_{x} \boldsymbol{U}_{\boldsymbol{x}} \\
2^{t} \boldsymbol{x}_{i}{ }^{t} \boldsymbol{U}_{\boldsymbol{y}} \boldsymbol{U}_{\boldsymbol{y}} \\
\left.{ }^{t} \boldsymbol{x}_{i}{ }^{t} \boldsymbol{U}_{x} \boldsymbol{U}_{y}+{ }^{t} \boldsymbol{U}_{\boldsymbol{y}} \boldsymbol{U}_{x}\right)
\end{array}\right]
$$

次に, 汎関数 (32) の変分を考元る。まず $H$ の第 1 変分をつくると

$$
\begin{aligned}
\delta H & =\delta \sqrt{g_{x x} g_{y y}-g_{x y}{ }^{2}} \\
& =\frac{1}{2 H}\left(\delta g_{x x} g_{y y}+g_{x x} \delta g_{y y}-2 g_{x y} \delta g_{x y}\right) \\
& =\frac{1}{2 H}\left\{\delta g_{x x} \delta g_{y y} \delta g_{x y}\right\}\left[\begin{array}{ccc}
0 & 1 & 0 \\
1 & 0 & 0 \\
0 & 0 & -2
\end{array}\right]\left\{\begin{array}{l}
g_{x x} \\
g_{y y} \\
g_{x y}
\end{array}\right\}
\end{aligned}
$$

ここで,

$$
\begin{aligned}
& \boldsymbol{D}=\left[\begin{array}{ccc}
0 & 1 & 0 \\
1 & 0 & 0 \\
0 & 0 & -2
\end{array}\right] \\
& \boldsymbol{\sigma}=\left\{\begin{array}{lll}
\sigma_{1} & \sigma_{2} & \sigma_{3}
\end{array}\right\}=(1 / 2 H) \boldsymbol{D g}
\end{aligned}
$$

とすると, 式 (40) は式 (41), 式 (42) および式 (38) を用いて

$$
\delta H={ }^{t} \delta \boldsymbol{g} \cdot \boldsymbol{\sigma}={ }^{t} \delta \boldsymbol{x}_{i}{ }^{t} \boldsymbol{V} \boldsymbol{\sigma}
$$

さらに，式（29）を用いて式（43）を変形すると

$$
\delta H={ }^{t} \delta \boldsymbol{a}_{i}{ }^{t} \boldsymbol{\Lambda}^{t} \boldsymbol{V} \boldsymbol{\sigma}
$$

となる。これを式（32）の変分式に代入すると

$$
\delta \Pi_{e}={ }^{t} \delta \boldsymbol{a}_{i}\left(n_{0}{ }^{t} \Lambda \int{ }^{t} \boldsymbol{V} \sigma d x d y\right)
$$

結局 $\delta \Pi_{e}=0$ より停留式は次式となる。

$$
n_{0}{ }^{t} \boldsymbol{\Lambda} \int{ }^{t} \boldsymbol{V} \boldsymbol{\sigma} d x d y=0 .
$$

次に, Newton-Raphson 法を用いるときの，増分方程 式を求める。まず式（46）の被積分項の増分を考える。

$$
\begin{aligned}
& d\left({ }^{t} \boldsymbol{V} \boldsymbol{\sigma}\right)={ }^{t} \boldsymbol{V} \cdot d \boldsymbol{\sigma}+\mathrm{d}^{t} \boldsymbol{V} \cdot \boldsymbol{\sigma} \\
& ={ }^{t} \boldsymbol{V} \cdot d \sigma+\left[\begin{array}{l}
{ }^{t} d \boldsymbol{x}_{i} \cdot 2{ }^{t} U_{x} U_{x} \\
{ }^{t} \mathrm{~d} x_{i} \cdot 2{ }^{t} U_{y} U_{y} \\
{ }^{t} d \boldsymbol{x}_{i} \cdot\left({ }^{t} U_{x} U_{y}+{ }^{t} U_{y} U_{x}\right)
\end{array}\right] \sigma \\
& ={ }^{\imath} \boldsymbol{V} \frac{\boldsymbol{D}}{2} d\left(\frac{\boldsymbol{g}}{\boldsymbol{H}}\right) \\
& +\left[2^{t} \boldsymbol{U}_{x} \boldsymbol{U}_{x} d \boldsymbol{x}_{i} \quad 2^{t} \boldsymbol{U}_{y} \boldsymbol{U}_{y} d \boldsymbol{x}_{i}\right. \\
& \left.\left.{ }^{(t} \boldsymbol{U}_{x} \boldsymbol{U}_{y}+{ }^{t} \boldsymbol{U}_{y} \boldsymbol{U}_{x}\right) d \boldsymbol{x}_{i}\right] \boldsymbol{\sigma}
\end{aligned}
$$




$$
\begin{aligned}
& ={ }^{t} \boldsymbol{V} \frac{\boldsymbol{D}}{2 H^{2}}(d \boldsymbol{g} H-\boldsymbol{g} d H)
\end{aligned}
$$

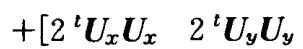

$$
\begin{aligned}
& \left.\left({ }^{t} \boldsymbol{U}_{x} \boldsymbol{U}_{y}+{ }^{t} \boldsymbol{U}_{y} \boldsymbol{U}_{x}\right)\right]^{t} \sigma d \boldsymbol{x}_{i} \\
& =\left(\frac{1}{2 H}{ }^{t} \boldsymbol{V D} \boldsymbol{V}-\frac{1}{H}{ }^{t} \boldsymbol{V}_{\boldsymbol{\sigma}} \cdot{ }^{t} \boldsymbol{\sigma} \boldsymbol{V}\right) d \boldsymbol{x}_{i}
\end{aligned}
$$

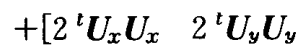

$$
\begin{aligned}
& \left.{ }^{t} \boldsymbol{U}_{\boldsymbol{x}} \boldsymbol{U}_{\boldsymbol{y}}+{ }^{t} \boldsymbol{U}_{\boldsymbol{y}} \boldsymbol{U}_{\boldsymbol{x}}\right]^{\boldsymbol{t}} \boldsymbol{\sigma d} \boldsymbol{x}_{\boldsymbol{i}} \cdots \cdot(47)
\end{aligned}
$$

上式に式（29）の増分式 $d x_{i}=\boldsymbol{\Lambda} d \boldsymbol{a}_{i}$ を代入し，さら に式（46）の増分式に代入すると次式が得られる。

$$
\boldsymbol{K} \cdot d \boldsymbol{a}_{i}=d \boldsymbol{f}_{1}^{*}
$$
ここに,

$$
\begin{aligned}
& \boldsymbol{K}=\boldsymbol{K}_{e}+\boldsymbol{K}_{g} \\
& \boldsymbol{K}_{e}=n_{0}{ }^{t} \boldsymbol{\Lambda} \int\left(\frac{1}{2 H}{ }^{t} \boldsymbol{V} \boldsymbol{D} \boldsymbol{V}-\frac{1}{H}{ }^{t} \boldsymbol{V} \boldsymbol{\sigma} \cdot{ }^{t} \boldsymbol{\sigma} \boldsymbol{V}\right) \boldsymbol{\Lambda} d x d y
\end{aligned}
$$

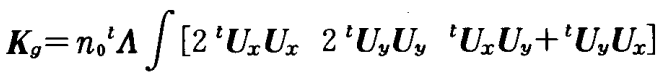

$$
\begin{aligned}
& \cdot \boldsymbol{\sigma} \Lambda d x d y \\
& d \boldsymbol{f}_{i}^{*}=-n_{0}{ }^{t} \Lambda \int{ }^{t} \boldsymbol{V} \boldsymbol{\sigma} d x d y
\end{aligned}
$$

である。

式 (48) が各ステップの増分方程式で, 式 (52) は不 釣合量を表す。計算は $d \boldsymbol{f}_{i}^{*}$ が 0 に近くなるまで反復さ せる。

\section{4. 数值解析例}

\section{1 回転懸垂曲面}

極小曲面の解析例として, 回転懸垂曲面を解析した(図 -3)。この曲面は, 極小曲面の解析解が得られている例 としてよく知られているが, 数值解析上は, 曲面の勾配 が大きくなることや，2価となるために収束性がよくな い例と言わ机ている。

分割数は, 周方向に 24 分割, 高さ方向に 10 分割であ る。初期曲面は安定解 (汎関数 (4) が極小となる解) の時は円筒面とし，不安定解（汎関数（4）が極大とな る解）の時は次のようにして求めた。極小曲面の $z=$ 0.5 における位置をくびれ位置とすると, 安定解の極小 曲面のくびれ位置を半径方向に強制移動させて解析した 時の曲面を初期曲面とした。強制移動量はこの初期曲面

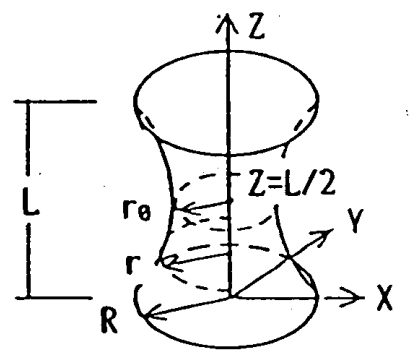

図一3 回転懸垂曲面
をもとにして極小曲面を解析した時に解が収束するよう な位置までの距離とするが，この場合にはあらかじめ理 論解がわかっているのでその近傍の位置 $(r=0.3)$ ま で移動させた（図一4）。方向余弦は各節点から回転軸方 向にかつ $X Y$ 平面に平行な方向にとった。

解析結果を表一1に示す。表中の数値は曲面位置 $r$ を円の半径 $R$ で無次元化した量である。本解析解と理 論解 ${ }^{51}$ は, 安定解と不安定解の両方の場合に対して, よ く一致していることが分かる。図一5, 図一6にそれぞ れ極小曲面とその断面図を示した。図一7は, 円の高さ $L / R$ を変えたときの鞍点の位置 $r_{0} / R$ の変化の様子を 示したものである。数値解（○）は理論解 ${ }^{151}$ とよく一致 している。曲面が存在する限界高さは, 本解析解は 0.6550 , 理論解 ${ }^{(5), 16)} 0.6628$ であった。

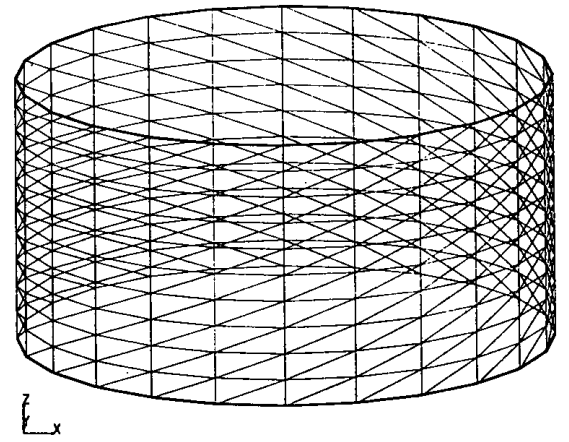

（a）安定解

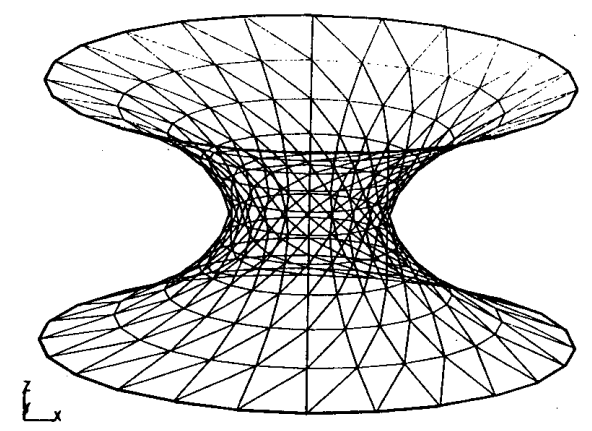

(b) 不安定解

图-4 初期曲面 (回転懸垂曲面)

表一1 極小曲面の数値解析結果（回転懸垂曲面）

\begin{tabular}{cccrc}
\hline \multirow{2}{*}{$Z / R$} & \multicolumn{2}{c}{ 安定解 } & \multicolumn{2}{c}{ 不安定解 } \\
& 本解析解 & 理論解 & 本解析解 & 理論解 \\
\hline 0.50000 & 0.84542 & 0.84834 & 0.23484 & 0.23510 \\
0.40000 & 0.85143 & 0.85424 & 0.25644 & 0.25669 \\
0.30000 & 0.86955 & 0.87202 & 0.32522 & 0.32542 \\
0.20000 & 0.90004 & 0.90194 & 0.45380 & 0.45393 \\
0.10000 & 0.94332 & 0.94440 & 0.66577 & 0.66582 \\
0.00000 & 1.00000 & 1.00000 & 1.00000 & 1.00000 \\
\hline
\end{tabular}




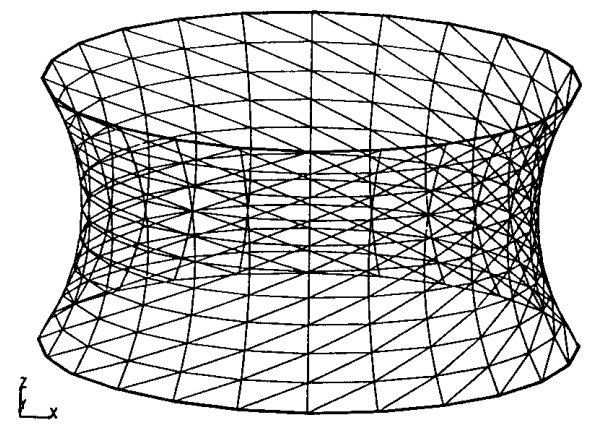

(a) 安定解

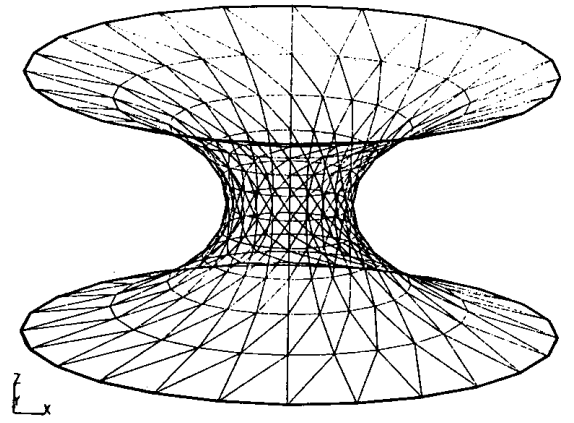

(b) 不安定解

図一5 極小曲面（回転懸垂面）

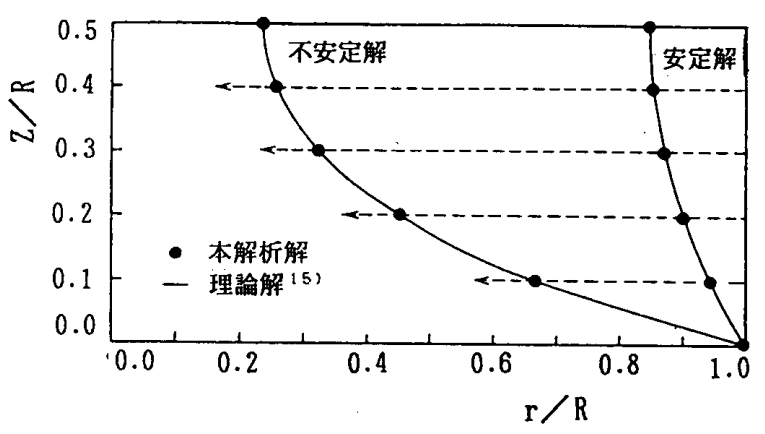

図一6 極小曲面の断面図（回転䯚垂面）

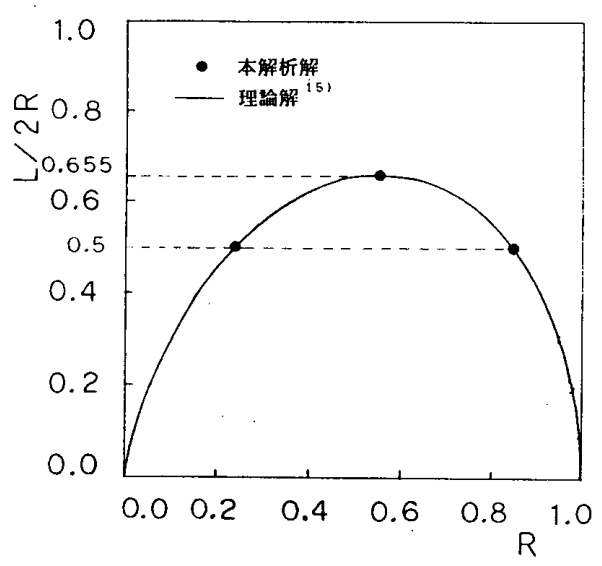

図一7 極小曲面の鞍点の位置（回転懸垂曲面）

\subsection{Wiener-Douglas 問題}

Wiener-Douglas 問題とは, 図一8に示すような $2 つ$

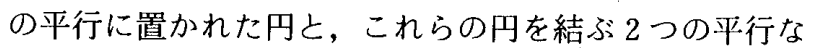
直線とを境界に持つ極小曲面を求める問題である。この

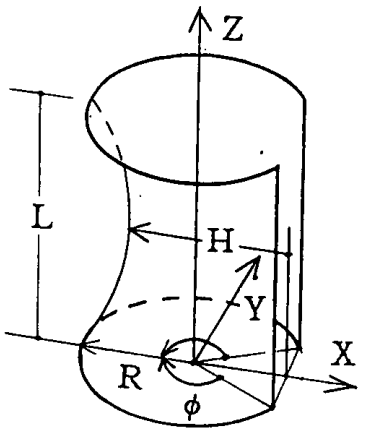

図一8 Wiener-Douglas 問題

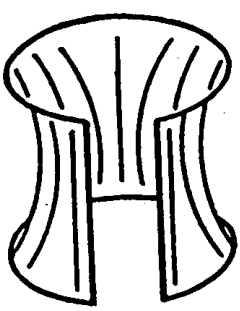

安定解 1

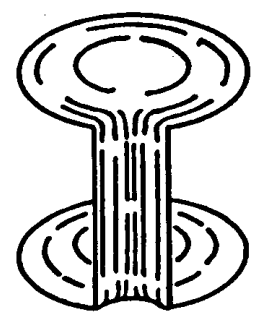

安定解 2
図一9 二つの安定解 (Wiener-Douglas 問題) ${ }^{9)}$

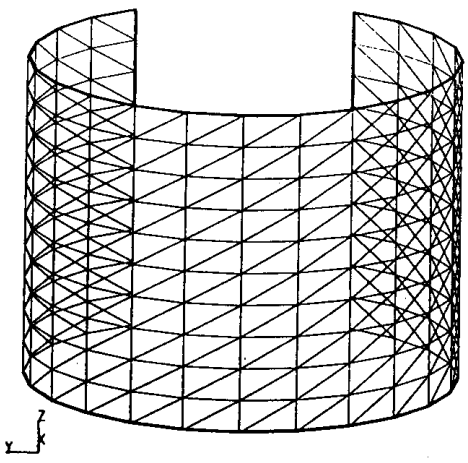

(a) 安定解 1

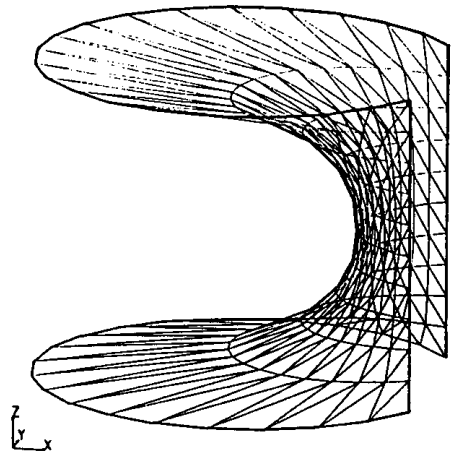

(b) 安定解 2

図一10 初期曲面 (Wiener-Douglas 問題)

ような境界では, 2 つの円の間隔 $L$ と半開角 $\phi$ との值 によって二種類の安定的な極小曲面が生じる場合がある ことが知られている ${ }^{9)}$ (図一9, 安定解 1 と安定解 2 )。 本解析では $L / R=1.5, \phi=150^{\circ}$ とした。 


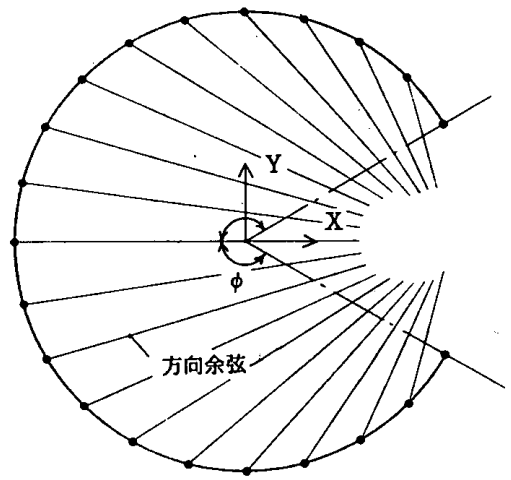

図一11 方向余弦（Wiener-Douglas 問題）

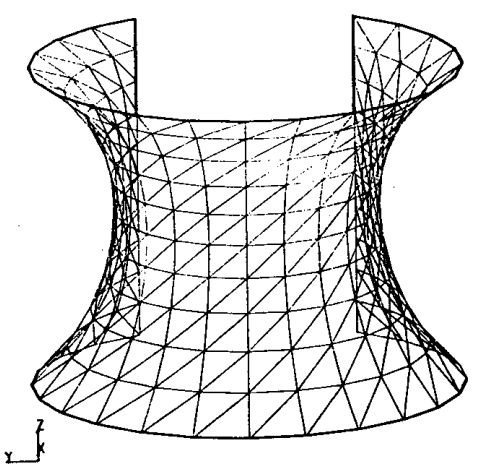

(a) 安定解 1

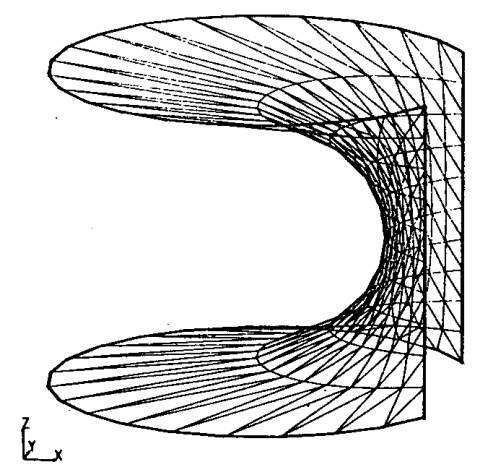

(b) 安定解 2

図一12 極小曲面 (Wiener-Douglas 問題)

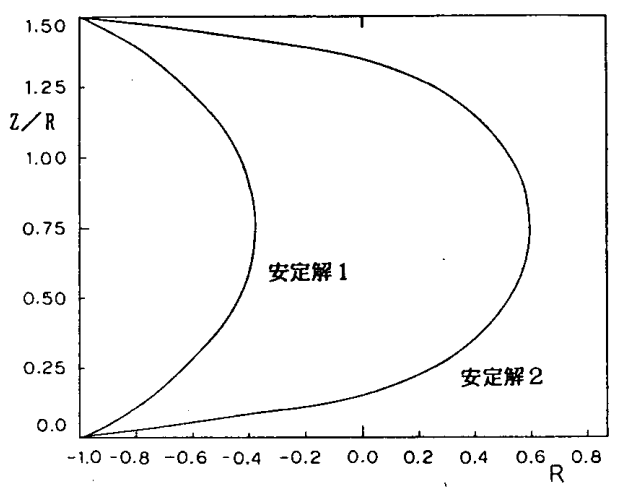

図一13 極小曲面の断面図 (Wiener-Douglas 問題)

分割数は円周方向には等間隔で 20 分割, $z$ 方向には 10 分割とした。初期曲面は図一10に示すようにとり， 方向余弦は各節点から図一11に示すような方向にかつ

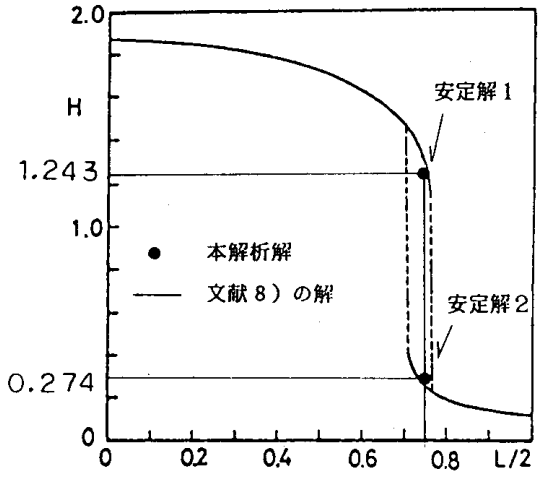

図一14 極小曲面の鞍点の位置 ${ }^{8 !}$ (Wiener-Douglas 問題)

表一2 極小曲面の鞍点の座標の比較 (Wiener-Douglas 問題)

\begin{tabular}{lcc}
\hline & 本解析解 & 文献 8) の解 \\
\hline 安定解 1 & 1.243 & 1.260 \\
安定解 2 & 0.274 & 0.262 \\
\hline
\end{tabular}

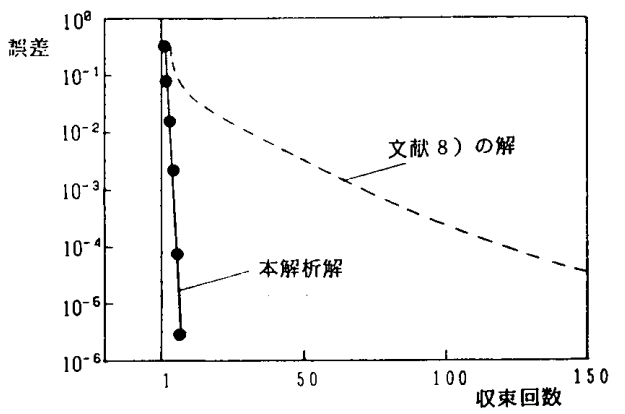

図一15 収束回数と誤差 (Wiener-Douglas 問題, 安定解 1 )

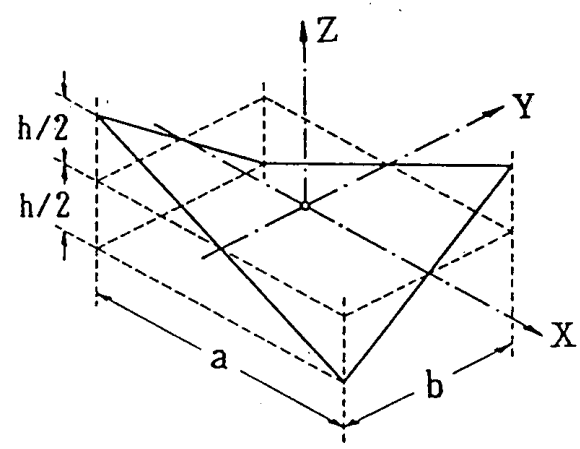

図一16 HP 曲面問題の境界形状

$x y$ 平面に平行とした。図一12 に極小曲面を示した。図 -12 は文献 9）の概念図（図一9）とよく似ていること が分かる。図一13 は $y=0$ における断面図を示した。図 -14 と表一 2 にそれぞれ鞍点の位置 (本解析解○印) と その值を示し, 文献 8 ) の值と比較した。表中の数値は 鞍点の位置 $H$ を円の半径 $R$ で無次元化した量である。 これらから, 本解析解は文献 8) の結果とほぼ一致して いることがわかる。図一15 は, 安定解 1 の場合の収束 回数と誤差の関係を示したものであるが，誤差を $10^{-4}$ に収れんさせるための収束回数は, 本解析では 5 回, 文 献 8）では約 150 回であり，本解析の収束性は文献 8) 


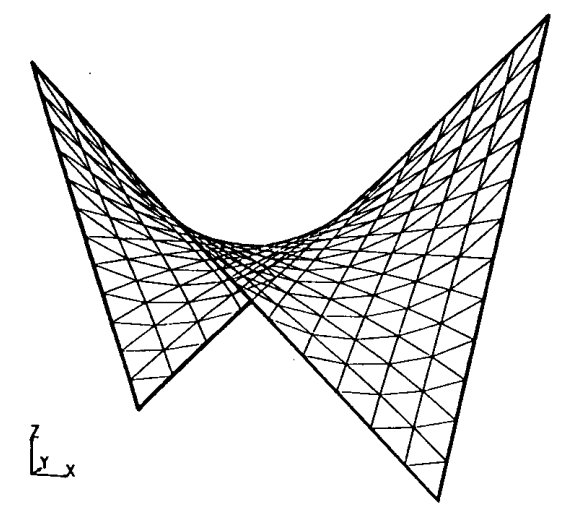

図一17 極小曲面 (HP 曲面問題) $H=1.0$

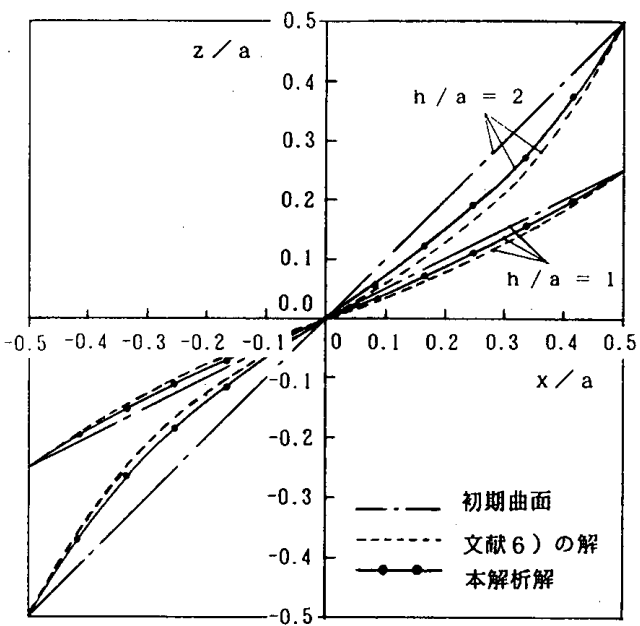

図一18 極小曲面の断面図（HP 曲面問題） $y=a / 4$

と比較して極めてよいことが分かる。安定解 2 の場合も ほぼ同様な傾向であった。本解析の収束性がよい理由は, 未知数に対する方向余弦の与え方が適切であったためと 考えられる。

\section{4. $3 \mathrm{HP}$ 曲面}

図一16に示すような, HP 曲面を構成する 4 辺を境 界に持つ極小曲面を求める。

分割数は $x, y$ 方向共に 12 分割, 初期曲面は HP 曲 面 $z=2 h(x / a)(y / b)$ とした。方向余弦はすべての節点 で $(0,0,1)$ とした。

図-17に，H=1.0の場合の極小曲面を示した。図一 18 に， $y=4 / a$ に打ける断面図を示した。本解析解は文 献 6) の值とほぼ一致していることが分かる。

\section{5. まとめ}

極小曲面形状を求めるための一つの数值解析手法を提 案しその特徴を具体例より検討した。本手法は極小曲面 の汎関数として一般の曲面パラメータで表現した曲面の 汎関数を用いている。汎関数から導かれた非線形微分方 程式の解の性質から極小曲面の未知量は初期曲面から任 意の方向に設定された方向余弦方向の距離として表現で きることを示した。本解析法の特徴は次のとおりである。
（1）初期曲面と曲面上の方向余弦は，次にのべる制約 を満足する範囲で任意に設定できる。ただし，方向余弦 の設定に際しては, 求まる極小曲面が任意の 2 節点で指 定した方向余弦の交点と初期曲面との間に存在するよう に選ばなくてはならないという制約がある。

（2）解析する未知量は，1 節点あたり 1 変数であり, 従来の 3 変数と比較して取り扱いが容易になる。

（3）解の収束過程で特別な操作を行わずに，確実に収 束解が得られる。

謝 辞

本報告をまとめるにあたって，貴重なご意見を頂いた 横浜国立大学教授 石井一夫博士，名古屋大学助教授 大 森博司博士および原稿作成にあたり多大な労力と有意義 な示唆を与えて頂いた株式会社フジ夕 萩原伸幸氏に深 く感謝致します。

\section{参考文献}

1) Courant, R. and Hilbert, D. : Methoden der Mathematischen Physik, Berlin, Springer, 1937

2) Batemann, H. : Partial differential equations of mathematical physics, New York, Dover, 1931

3）森 正武：有限要素法とその応用, §13.4 極小曲面問題, 応用数学叢書, 岩波書店, pp. 157 163，1980

4) Greenspan, D. : On approximating extremals of functionals, Part I, ICC Bull., V.4, MR 32 8526,.pp. 99 $\sim 120,1965$

5) Concus, P. : Numerical solution of the minimal surface equation, Math. Comp., V.21, MR 37 4968, pp. 340 $\sim 350, \quad 1967$

6) Otto, F. and Trostel, R. : Tensile Structures Vol. I, The M.I. T. Press, pp. $290 \sim 296,1967$

7) Ishii, K and Suzuki, T. : Shape of Membrane. Structures, Proc. of IASS Pacific Symposium on Tension Structures and Space Fremes, Tokyo Japan, Oct. 1971.

8) Hinata, M., Shimasaki, M. and Kiyono, T. : Numerical solution of Platea's problem by a finite element method, Math. Comp., V.28, No. 125, pp. 45 60, 1974.

9) Courant, R. : Dirichlet's Principle, Conformal Map-

- ping, and Minimal Surfaces, Interscince, New York, 1950

10) Haug, E., and Powell, G.H. : Finite element analysis of nonlinear membrane structures, Proc. of IASS Pacific Symposium on Tension Structures and Space Frames, Tokyo Japan, 1971. 10

11) Barnes, M.R. : Form-finding of minimal surface membranes, Proc. of IASS World Congress on Space Enclosures, Montreal Canada, 1976.7

12）石井一夫：膜構造の形状解析, 日本建築学会大会学術講 演梗概集 (関東) pp. 2599 2600，1984.10

13）安宅信行：膜構造の形態の理論について, 日本建築学会 学術講演梗概集, 1987.10.

14）本間俊雄，鈴木俊男，荒井高志，中山昌尚，坂根伸夫： 
膜構造における極小曲面問題について, 第 2 回シェルと 空間構造に関する日韓コロキウム, pp. $111 \sim 118$, 1987. 8

15）大森博司, 萩原伸幸, 松井徹哉, 松岡 理: 有限要素法 による極小曲面の数値解析, 膜構造研究論文集, pp.1
10, 1988

16）佐藤幸平: 面積最小の問題の石鹼膜実験, 数学セミナ一, p. $64,1973.11$

(1990 年 11 月 10 日原稿受理, 1991 年 5 月 18 日採用決定) 